\title{
IMPLEMENTASI PENILAIAN DAUR HIDUP PRODUK SUSU SAPI SEGAR (STUDI KASUS KOPERASI PETERNAK MJM)
}

\section{IMPLEMENTATION OF LIFE CYCLE ASSESSMENT OF FRESH COW MILK PRODUCTS (CASE STUDY OF KOPERASI MJM)}

\author{
Bunga Cahyaputri*), Mohamad Yani, dan Sugiarto \\ Program Studi Teknik Industri Pertanian, Fakultas Teknologi Pertanian, Institut Pertanian Bogor \\ Kampus IPB Dramaga, Bogor 16680, West Java, Indonesia \\ *Email: bunga_tip18@apps.ipb.ac.id
}

Makalah: Diterima 30 Desember 2021; Diperbaiki 01 April 2021; Disetujui 15 April 2021

\begin{abstract}
Milk industry in Indonesia grows every year due to the population growth, income increases, and the awareness on milk consuming benefit. Milk production in Indonesia comes from small and medium animal farmers, requiring cooperation to improve the quality of dairy products in Indonesia. Member of Cooperation Mitra Jaya Mandiri (MJM) is small local animal farmers which their activities are still done manually. Activities of MJM Cooperation, animal farmers, and milk transportation have an impact on the environment. The objective of this research was to identify inputs, outputs, and environmental impacts in the production of fresh milk (case study of MJM Cooperation). The methods used were life cycle assessment ( $L C A)$ with three impact categories, i.e. global warming $(G W P)$, eutrophication potential (EP), and acidification potential (AP). The boundary of LCA study was cradle to gate, which includes feed production, dairy farming activities, transportation of milk to MJM, cooling of milk in MJM Cooperation and transportation of milk to factory. Based on LCA results, the environmental impact of GWP, EP, and AP 1 were $\mathrm{kg}$ of Coperation MJM fresh milk equals to $3.16 \mathrm{~kg} \mathrm{CO}_{2} \mathrm{eq}, 0.0119 \mathrm{~kg} \mathrm{PO}_{4}{ }^{3-}$, and $0.00639 \mathrm{~kg} \mathrm{SO}_{2}$ eq, respectively. The highest environmental impact in these three categories came from dairy farming unit. Processing cow feces, or choosing feed additive that more environmentally friendly can reduce the environmental impact.
\end{abstract}

Key words: cradle to gate, diary farm, environmental impact, fresh milk, life cycle assessment

\section{ABSTRAK}

Pertumbuhan sektor industri pengolahan susu di Indonesia meningkat setiap tahunnya. Hal ini dikarenakan pertumbuhan penduduk, peningkatan penghasilan masyarakat Indonesia serta kesadaran manfaat konsumsi susu. Produksi susu di Indonesia banyak berasal dari peternak kecil maupun sedang, sehingga memerlukan koperasi untuk meningkatkan mutu produk susu di Indonesia. Koperasi Mitra Jaya Mandiri (MJM) beranggotakan puluhan peternak skala kecil. Kegiatan koperasi, para peternak, dan transportasi susu memberikan dampak terhadap lingkungan. Studi ini bertujuan untuk mengidentifikasi input, output, dan dampak lingkungan dalam produksi susu segar (studi kasus koperasi MJM). Metode yang digunakan adalah penilaian daur hidup produk (LCA) terhadap tiga kategori dampak, yakni pemanasan global (GWP), potensi eutrofikasi (EP), dan potensi asidifikasi (AP). Batasan kajian LCA dari cradle to gate, yang meliputi produksi pakan, kegiatan peternakan sapi perah, transportasi susu ke koperasi, pendinginan susu di koperasi, dan transportasi susu ke pabrik. Berdasarkan hasil LCA, dampak lingkungan GWP, EP dan AP masing-masing adalah1 kg susu segar Koperasi MJM sama dengan 3,16 $\mathrm{kg} \mathrm{CO}_{2}$ eq, $0,0119 \mathrm{~kg} \mathrm{PO}_{4}{ }^{3-}$, dan $0,00639 \mathrm{~kg} \mathrm{SO}_{2}$ eq. Tahap kegiatan peternakan sapi perah memiliki dampak lingkungan tertinggi pada tiga kategori tersebut. Potensi pengurangan dampak lingkungan dapat dilakukan dengan pengolahan kotoran sapi, atau pemilihan bahan pakan tambahan yang lebih ramah lingkungan.

Kata kunci : cradle to gate, dampak lingkungan, LCA, susu segar, peternakan sapi perah

\section{PENDAHULUAN}

Indonesia merupakan salah satu negara dengan angka pertumbuhan penduduk yang tinggi. Jumlah penduduk yang meningkat dari tahun 2010 membuat permintaan terhadap berbagai kebutuhan hidup terus meningkat (BPS, 2019). Pertumbuhan ekonomi dan teknologi juga terus meningkat yang menyebabkan kebutuhan manusia semakin meningkat, khususnya pangan. Perkembangan pangan di Indonesia dipengaruhi oleh gaya hidup masyarakat yang peduli akan tingkat pendidikan, pemenuhan gizi yang baik dan perkembangan teknologi. Pangan dalam zaman ini tidak hanya bertujuan untuk memenuhi rasa kenyang, akan tetapi sudah berubah menjadi pemenuhan gizi yang baik untuk tubuh. Menurut Foley et al. (2010), meningkatnya permintaan bahan makanan yang disebabkan oleh pertumbuhan populasi dunia dan perubahan pola makan (penambahan konsumsi 
daging dan susu) mendorong intensifikasi produksi, sementara ancaman lingkungan seperti perubahan iklim, hilangnya keanekaragaman hayati, degradasi tanah dan air tawar menumbuhkan kekhawatiran publik tentang lingkungan pertanian.

Konsumsi susu masyarakat Indonesia terbilang rendah sekitar 11,09 L/kapita/tahun dibandingkan konsumsi susu sejumlah negara di ASEAN sekitar $20 \mathrm{~L} / \mathrm{kapita} / \mathrm{tahun}$. Walaupun begitu, pertumbuhan sektor industri pengolahan susu pada tahun 2013 sebesar $12 \%$ yang mengalami peningkatan dibandingkan pada tahun sebelumnya sebesar 10\%. Berdasarkan data Kemenperin 2014, ekspor dan impor produk olahan susu tahun 20112013 semakin meningkat.

Sebagian besar produksi susu hasil peternakan rakyat di Indonesia disalurkan ke koperasi/KUD persusuan. Susu mengalami proses pendinginan di koperasi selanjutnya susu dipasarkan kepada Industri Pengolah Susu (IPS). Peternakan di Indonesia lebih banyak usaha peternakan rakyat yang dilakukan dengan alat yang sederhana, manajemen yang konvensional (Firman, 2007).

Kegiatan di industri susu dan peternakan sapi perah menimbulkan masalah baru yaitu pencemaran lingkungan. Koperasi yang termasuk dalam siklus produksi susu juga menghasilkan polutan. Hal ini erat kaitannya dengan adanya kegiatan pendinginan, penyediaan konsentrat, dan adanya kegiatan transportasi pengumpulan susu dari peternak. Pada kegiatan peternakan menghasilkan beberapa gas polutan berupa hidrogen sulfida, nitrogen, $\mathrm{CO}_{2}$ dan $\mathrm{CH}_{4}$. Gas tersebut dapat menimbulkan bau tak sedap dan mengganggu kesehatan manusia. Limbah ternak yang tidak diolah ini biasanya akan terbuang ke perairan yang akan mencemari lingkungan perairan karena terdapat mikroorganisme patogenik pada limbah ternak (Widyastuti, 2013). Bagian hulu dari industri susu di Indonesia yaitu sektor peternakan sapi perah, memberikan kontribusi sebesar 3,8\% terhadap potensi gas rumah kaca (Permana, 2012).

Dalam beberapa dekade ini, kesadaran masyarakat terhadap lingkungan juga semakin meningkat. Sebuah prinsip baru yaitu ramah lingkungan telah menjadi parameter daya saing dalam industri yang tidak dapat dihindarkan. Masyarakat dunia mulai merasakan dampaknya secara langsung sehingga persoalan lingkungan mulai menjadi perhatian dunia. Pembentukan United Nations Framework Convention on Climate Change (UNFCCC) merupakan usaha yang dilakukan untuk melakukan minimalisasi kenaikan suhu muka bumi. Selain itu diadakan Conference of the Parties (COP) yang menghasilkan Protokol Kyoto, salah satu isinya adalah kesepakatan antar negara, termasuk negara Indonesia, untuk mengurangi emisi udara. Komitmen yang dibuat oleh Indonesia yaitu menurunkan kadar emisi gas sebesar 26\% di tahun 2020. Pelaksanaan komitmen tercantum dalam Peraturan Presiden Nomor 61 Tahun 2011 tentang Rencana Aksi
Nasional Penurunan Emisi Gas Rumah Kaca (RAN GRK) dan Peraturan Presiden Nomor 71 Tahun 2011 tentang Penyelenggaraan Inventarisasi Gas Rumah Kaca Nasional (Perpres, 2011)

Peraturan yang dibuat pemerintah mendorong industri untuk menjadi industri ramah lingkungan dan berkelanjutan. Terdapat beberapa metode untuk menilai dampak lingkungan yang terkait dengan sistem pangan. Salah satu metode yang sesuai adalah Life Cycle Assessment (LCA). Metode LCA digunakan untuk berbagai produk karena dilakukan analisis yang bertahap dimulai dari analisis input, output dan dampak lingkungan dalam proses produksi. LCA juga merupakan salah satu metode untuk mengetahui tingkat keberlanjutan suatu produk (Christie et al., 2011). LCA merupakan metode secara menyeluruh untuk mengetahui sumber daya yang digunakan, konsumsi energi, biaya dan menganalisis dampak lingkungan dalam satu siklus hidup. Satu siklus hidup ini, disebut cradle to grave, dimulai dari pengambilan bahan baku dari bumi sampai produk digunakan oleh konsumen maupun hasil samping yang dikembalikan ke bumi (Harjanto et al., 2012). Metode LCA membantu dalam mengetahui potensi limbah yang akan muncul, pertimbangan pengambilan keputusan serta penggunaan energi dan bahan baku yang diperlukan selama proses produksi produk tersebut. LCA dapat menganalisis pengurangan dampak dari alternatif perbaikan yang akan dilakukan (Purwaningsih, 2016).

Penelitian LCA pada susu segar dilakukan di koperasi yang beranggotakan para peternak sapi perah skala kecil. Tujuan penelitian ini adalah untuk mengidentifikasi sumber daya yang digunakan, energi, dan jumlah emisi yang dihasilkan dari produksi susu, menghitung dampak yang ditimbulkan terhadap lingkungan serta memberikan rekomendasi untuk alternatif perbaikan kepada para peternak dan koperasi.

\section{METODE PENELITIAN}

Penelitian dilakukan di Koperasi Serba Usaha (KSU) Mitra Jaya Mandiri (MJM) dan para peternak daerah Rancabali yang menjadi anggota KSU MJM. Data yang digunakan dalam penelitian ini terdiri dari data primer dan data sekunder. Data primer merupakan data yang didapat dari hasil wawancara langsung serta observasi lapang dengan peternak daerah Rancabali dan pekerja koperasi MJM. Lima kelompok peternak yang dianalisis yaitu kelompok Sinapeul, Barutunggul, Cibodas 1, Cibodas 2 dan Cibodas 3. Rata-rata pemberian pakan dibedakan menjadi tiga kategori berdasarkan kuantitas pakan yaitu pakan 1 (banyak), pakan 2 (sedang), dan pakan 3 (sedikit).

Pemberian pakan (takaran rumput, konsentrat dan bahan tambahan pakan), penggunaan air, penggunaan lahan untuk penanaman rumput dan kebutuhan transportasi pengambilan rumput 
merupakan data primer. Data sekunder berasal dari dokumen koperasi berupa data bahan baku, air, susu segar yang diproduksi, energi listrik dan peralatan pada setiap tahapan proses serta berasal dari hasil penelitian yang telah dipublikasikan sebelumnya.

Metode yang digunakan untuk perhitungan dampak dalam penelitian ini adalah LCA. Metode LCA dilakukan berdasarkan pedoman pelaksanaan LCA menurut Framework ISO 14040 (2006) yang terdiri dari empat tahap, yaitu :

\section{Definisi Tujuan dan Ruang Lingkup}

Penentuan tujuan dan ruang lingkup merupakan tahap awal dalam melakukan analisis LCA. LCA yang dikaji dibatasi dalam lingkup cradleto-gate, yaitu dari produksi pakan terutama rumput, kegiatan peternakan sapi perah sampai perah susu murni, kegiatan di koperasi sampai transportasi ke IPS. Unit fungsi digunakan untuk memberikan kondisi perbandingan yang terhubung ke input dan output (Castanheira et al., 2010). Unit fungsi yang digunakan dalam kajian LCA ini yaitu satu kg susu segar. Ruang lingkup dapat dilihat pada Gambar 1 dari alur proses yang dikaji. Ruang lingkup meliputi empat kelompok kegiatan yaitu penyediaan pakan, kegiatan di peternakan, kegiatan di koperasi dan transportasi. Tujuan analisis LCA yang dilakukan adalah mengetahui dampak lingkungan dalam satu siklus produksi susu segar.

\section{Inventarisasi Input Dan Output}

Analisis inventori merupakan bagian dari LCA yang berisi satu set data aliran bahan dan energi yang mengkuantifikasikan input dan output dari daur hidup produk selama 12 bulan. Sebagian data diperoleh dari hasil perhitungan dan data dari penelitian sebelumnya. Data sapi dihitung dari sapi perah yang sedang berproduksi. Data yang digunakan untuk analisis inventori sesuai dengan alur produksi di peternakan dan koperasi yang dapat dilihat pada Gambar 1.

\section{Analisis Dampak Lingkungan \\ Analisis dampak dilakukan untuk mengevaluasi dampak lingkungan yang dihasilkan berdasarkan hasil analisis inventori. Setiap input, output maupun proses dilakukan analisis emisi apa yang ditimbulkan dari masing-masingnya. Selanjutnya parameter emisi tersebut dikelompokkan berdasarkan kategori dampaknya. Ketiga kategori dampak yang digunakan dalam penelitian kali ini yaitu gas rumah kaca (GRK), asidifikasi, dan eutrofikasi. Beberapa parameter yang memiliki efek GRK yaitu $\mathrm{CO}_{2}, \mathrm{~N}_{2} \mathrm{O}$, dan $\mathrm{CH}_{4}$. Parameter tersebut akan dikonversi menjadi $\mathrm{CO}_{2}$-eq untuk menghitung dampak GRK.}

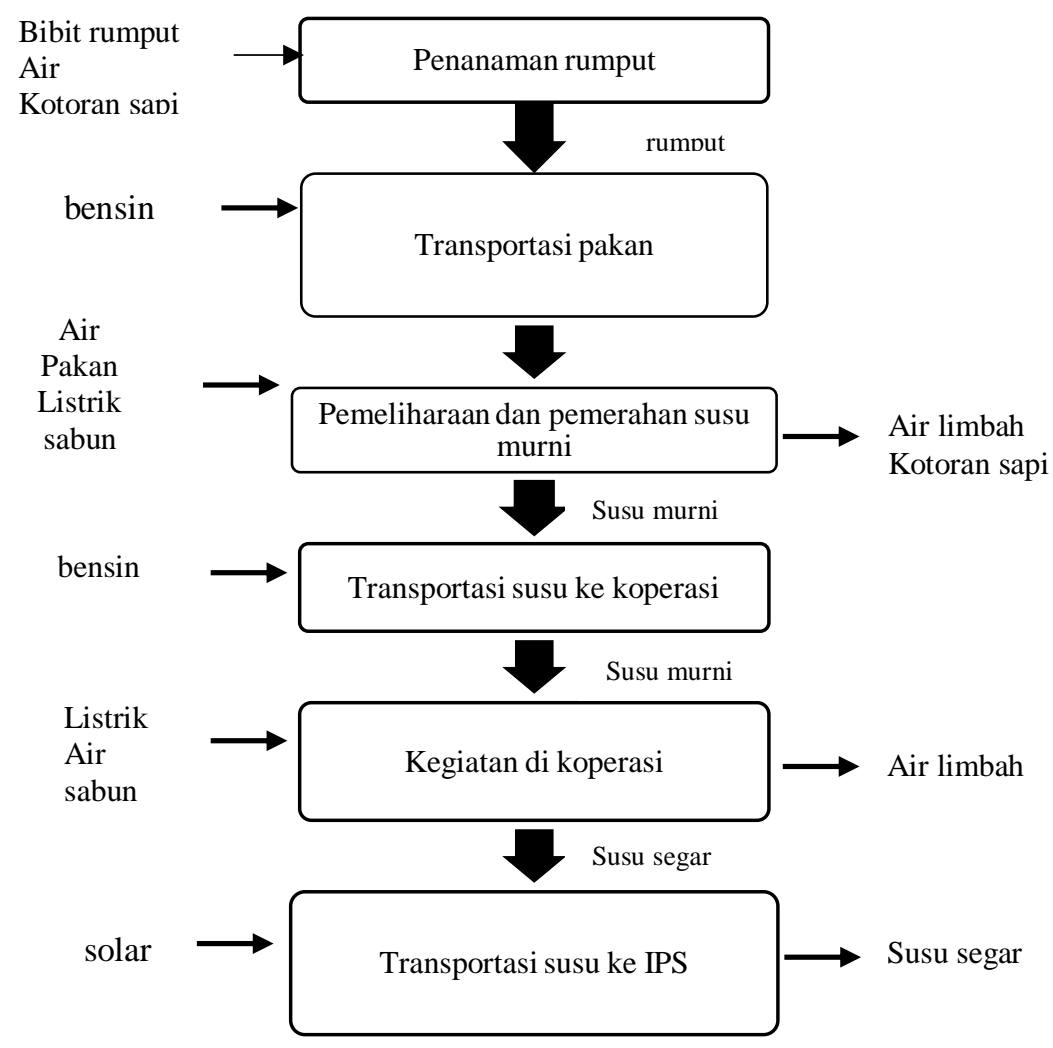

Gambar 1. Alur produksi peternakan dan koperasi 
Dampak terhadap asidifikasi dianalisis berdasarkan kandungan $\mathrm{SO}_{2}, \mathrm{NOx}$, dan $\mathrm{NH}_{3}$ yang dikonversi menjadi $\mathrm{SO}_{2}$-eq, sedangkan dampak eutrofikasi berdasarkan kandungan $\mathrm{NOx}, \mathrm{NH}_{3}, \mathrm{PO}_{4}{ }^{3-}$, dan nutrien ( $\mathrm{N}$ dan $\mathrm{P}$ ) yang dikonversi menjadi $\mathrm{PO}_{4}{ }^{3-}$ eq.

\section{Interpretasi Hasil}

Tahap selanjutnya adalah interpretasi hasil, evaluasi, dan analisis terhadap hasil analisis dampak dalam upaya untuk perbaikan dan mengurangi dampak negatif terhadap lingkungan. Hasil dari analisis dampak dilakukan identifikasi tahapan proses yang memberikan dampak yang siginifikan terhadap perubahan lingkungan (hotspot). Selanjutnya, dianalisis dengan beberapa alternatif perbaikan untuk melihat penurunan dampak lingkungan yang terjadi.

Pengolahan dan penyajian data dilakukan dengan menggunakan Microsoft Excel. Data-data yang digunakan dalam kajian LCA dimasukkan ke dalam data inventori sebagai data kuantitatif untuk melihat input dan output yang dihasilkan. Pengolahan data dilakukan menggunakan Simapro versi 9.0 dengan perhitungan emisi menggunakan metode CML 1A baseline V3.06.

\section{HASIL DAN PEMBAHASAN}

\section{Kegiatan Peternakan Sapi Perah Rancabali}

Kegiatan peternakan di Rancabali dibagi menjadi 3 bagian. Bagian pertama yaitu pembuatan pakan. Pakan yang diberikan berupa pakan hijau yaitu rerumputan, konsentrat sebagai pakan tambahan untuk memenuhi nutrisi serta bahan pakan tambahan lainnya seperti ampas tahu, onggok maupun dedak. Rata-rata peternak di Rancabali memberikan ampas tahu sebagai bahan pakan tambahan. Rumput diperoleh oleh peternak melalui penanaman rumput. Koperasi MJM memberikan fasilitas pengadaan konsentrat, tetapi tidak membuat konsentrat tersebut. Kegiatan penanaman rumput dilakukan di daerah kawasan perhutani dengan sistem menyewa tanah. Tahap awal dimulai dengan penanaman bibit rumput berupa stek batang dan pemberian pupuk dari kotoran sapi pada awal penanaman. Pemberian air secara alami melalui hujan. Setelah 2 bulan, peternak memanen rumput secara manual menggunakan sabit. Pemotongan dilakukan tidak sampai akar karena nanti tumbuh menjadi rumput baru yang bisa dipanen kembali. Pemanenan rumput kedua, ketiga dan seterusnya berselang 40 hari.

Kegiatan kedua yaitu pemeliharaan sapi perah. Bentuk kegiatan meliputi pemberian pakan, pemberian minum, pembersihan kandang, pembersihan ternak dan pemeriksaan kesehatan. Pemberian pakan biasanya 3 kali sehari yaitu pagi, siang, sore/malam. Pada pagi hari dan sore hari, sapi diberi makan rerumputan, konsentrat maupun makanan tambahan seperti dedak, onggok, ampas tahu. Pada siang hari, peternak hanya memberi makan rerumputan. Pemberian air minum dilakukan 3 kali sehari dengan menggunakan ember maupun langsung dari selang. Biasanya pembersihan kandang dilakukan 3 kali sehari dengan menggunakan air (menyemprotkan air) langsung dari selang air. Pembersihan ternak dilakukan sebelum pemerahan dengan menggunakan air selang dan sabun.

Kegiatan ketiga yaitu pemerahan susu sapi. Dalam kegiatan ini peternak membersihkan daerah puting sapi dan sekitarnya baik menggunakan sabun maupun menggunakan air hangat. Selanjutnya dilakukan proses pemerahan secara manual menggunakan tangan. Kecepatan pemerahan bergantung pada kecepatan tangan peternak. Terdapat ember sebagai tempat penampungan sementara dibawah puting sapi. Setelah selesai pemerahan, susu yang diember dituang ke dalam bejana susu yang sudah dibersihkan sebelumnya dengan air sabun dan dikeringkan. Selama penuangan susu ke dalam bejana susu, dilakukan penyaringan menggunakan kain maupun saringan yang mempunyai pori-pori sebesar serat kain. Setelah proses pemerahan dan penyaringan susu, bagian puting sapi dibasuh dengan air hangat. Bejana yang berisi susu akan dibawa ke pos penampungan susu di masing-masing kelompok. Di pos penampungan, mobil pengangkut susu tiap pagi dan sore datang untuk menerima susu dari peternak dan mengambil sampel susu dari masing-masing peternak digabung menjadi satu sampel kelompok. Peternak membawa bejana susunya kembali dan mencucinya untuk dipakai selanjutnya.

Transportasi susu dari peternak ke koperasi merupakan tahapan selanjutnya. Proses pengangkutan menggunakan mobil pick-up yang dimodifikasi dengan penambahan tangki susu kapasitas 2000 liter. Pengangkutan susu dilakukan setiap pagi dan sore dari satu kelompok peternak ke kelompok peternak lainnya. Mobil pengangkut membawa susu dari peternak ke koperasi dan disimpan sementara di tangki pendinginan susu. Tangki pendinginan ini bertujuan untuk menjaga kualitas susu murni sebelum dilakukan pengangkutan susu ke IPS (Industri Pengolah Susu). Pengangkutan susu ke IPS dilakukan malam hari menggunakan truk tangki susu dengan kapasitas 5000 liter. Koperasi MJM menyalurkan susu segar (dingin) ke dua IPS yaitu KPSBU (Koperasi Peternak Sapi Bandung Utara) Lembang dan PT. ISAM (Industri Susu Alam Murni).

\section{Analisis Inventori}

Pada tahap ini dilakukan analisis per unit proses. Alur kegiatan proses per unitnya dapat membantu untuk menganalisis input, output serta emisi yang dikeluarkan. Alur kegiatan di peternakan dan koperasi dapat dilihat pada Gambar 1. Kegiatan di peternakan dibagi menjadi tiga kategori pakan. Jumlah tenaga kerja sama dengan jumlah peternak. Pemberian pakan kepada sapi dihitung sesuai pakan yang diberikan ke sapi perah produksi setiap harinya. 
Tabel 1 menunjukkan jumlah peternak, jumlah sapi dan produksi susu dalam setahun untuk masingmasing kategori yang digunakan dalam analisis LCA susu segar.

Proses pembuatan pakan utama, yaitu rerumputan, dilakukan secara alami. Input kegiatan penanaman yaitu bibit rumput yang berasal dari ladang rumput peternak yang lain atau dari pemerintah, air hujan serta kotoran sapi tiga kali tabur selama 12 bulan. Lahan yang dibutuhkan untuk memenuhi kebutuhan rumput adalah 15 ha. Sekali tabur diperlukan kotoran sapi sebanyak $375 \mathrm{~kg}$ untuk 15 ha. Rumput yang sudah dipanen dikumpulkan menjadi per ikat dengan berat $40-50 \mathrm{~kg}$. Rumput dibawa menggunakan kendaraan motor. Sekali transportasi pengambilan rumput dapat memenuhi kebutuhan pakan satu sapi per hari (80-100 kg) sehingga peternak melakukan transportasi pengambilan rumput sebanyak sapi yang dimiliki. Jarak antara kandang dengan ladang rumput 2-3 km. Input untuk analisis dampak dimasukkan juga berat satu pengendara motor yaitu seberat $50 \mathrm{~kg}$.

Input yang dibutuhkan saat pemeliharaan sapi adalah air, pakan dan listrik. Pakan sudah termasuk di dalamnya rerumputan, konsentrat, dan pakan tambahan berupa ampas tahu. Pada tahap pemerahan, input yang diperlukan adalah air hangat untuk membersihkan ambing sapi sebelum diperah. Energi listrik diperlukan dalam penerangan kandang. Setiap 3 sapi memerlukan setidaknya 1 lampu dengan daya 5 watt selama 12 jam.

Output dari proses penanaman rumput adalah rumput yang menjadi input untuk kegiatan pemeliharaan sapi perah. Output dari kegiatan peternakan adalah susu murni, air limbah, serta kotoran sapi. Air limbah termasuk air bekas pembersihan kandang dan sapi serta pencucian milk can. Kotoran sapi yang dihasilkan sebanyak $25 \mathrm{~kg}$ per hari per sapi. Pemberian air minum untuk satu sapi sebanyak 24-25 L per hari. Kotoran sapi dan pemberian air minum diasumsikan sama karena ratarata bobot sapi perah produksi di Rancabali seberat 450-550 kg. Sebanyak $1.133 \mathrm{~kg}$ kotoran sapi berbentuk padat dibawa ke tempat penanaman rumput sebagai pupuk di awal penanaman. Air limbah dan kotoran sapi lainnya dibuang begitu saja mengalir ke sungai tanpa pengolahan. Data input dan output proses peternakan dapat dilihat pada Tabel 2 .

Transportasi susu membutuhkan bahan bakar solar untuk menjalankan mobil pick up. Jarak dari koperasi MJM ke 5 kelompok peternak di Rancabali lalu kembali ke koperasi MJM yaitu $20 \mathrm{~km}$. Sekali perjalanan penjemputan susu murni membawa 718,23 $\mathrm{kg}$ sehingga input transportasi untuk analisis dampak sebesar 14,36 tkm (ton.km).

Tabel 1. Pemberian pakan, jumlah peternak, jumlah sapi, dan produksi susu berdasarkan kategori pakan

\begin{tabular}{|c|c|c|c|c|c|c|}
\hline \multirow[b]{2}{*}{$\begin{array}{l}\text { Kategori } \\
\text { pakan }\end{array}$} & \multicolumn{3}{|c|}{ Pemberian pakan per hari/sapi } & \multirow{2}{*}{$\begin{array}{c}\text { Jumlah } \\
\text { peternak } \\
\text { (orang) }\end{array}$} & \multirow[b]{2}{*}{$\begin{array}{c}\text { Jumlah } \\
\text { sapi (ekor) }\end{array}$} & \multirow[b]{2}{*}{$\begin{array}{l}\text { Produksi susu } \\
\text { (L/tahun) }\end{array}$} \\
\hline & $\underset{\text { (kg) }}{\text { Rumput }}$ & $\begin{array}{c}\text { Konsentrat } \\
\text { (kg) }\end{array}$ & $\begin{array}{c}\text { Ampas } \\
\text { tahu (kg) }\end{array}$ & & & \\
\hline Pakan 1 & 100 & 6 & 12 & 10 & 14 & 123794 \\
\hline Pakan 2 & 80 & 4 & 10 & 52 & 73 & 383008 \\
\hline Pakan 3 & 60 & 2,5 & 8 & 12 & 16 & 36090,5 \\
\hline
\end{tabular}

Tabel 2. Data inventori proses peternakan selama 12 bulan

\begin{tabular}{|c|c|c|c|c|c|}
\hline Data & Satuan & Kategori 1 & Kategori 2 & Kategori 3 & Jumlah \\
\hline \multicolumn{6}{|l|}{ Input } \\
\hline Bibit rumput & bibit & 33.782 & 146.989 & 24.774 & 205.545 \\
\hline Kotoran sapi & $\mathrm{kg}$ & 186 & 810 & 137 & 1.133 \\
\hline Rerumputan & $\mathrm{kg}$ & 496.800 & 2.161 .600 & 364.320 & 3.022 .720 \\
\hline Konsentrat & $\mathrm{kg}$ & 972 & 3.524 & 495 & 153.068 \\
\hline Ampas tahu & $\mathrm{kg}$ & 1.944 & 8.810 & 1.584 & 378.392 \\
\hline Air pakan dan minum sapi & $\mathrm{L}$ & 119.232 & 648.480 & 145.728 & 913.440 \\
\hline $\begin{array}{l}\text { Air pembersihan kandang } \\
\text { dan sapi }\end{array}$ & $\mathrm{L}$ & 223.560 & 1.215 .900 & 273.240 & 1.712 .700 \\
\hline Listrik & $\mathrm{kWh}$ & 248 & 1313 & 293 & 1.855 \\
\hline Sabun & $\mathrm{kg}$ & 22 & 120 & 27 & 169 \\
\hline Air cuci milk can & $\mathrm{kg}$ & 2.9808 & 162.120 & 36.432 & 228.360 \\
\hline \multicolumn{6}{|l|}{ Output } \\
\hline Susu murni & $\mathrm{kg}$ & 127.136 & 393.349 & 37.064 & 557.550 \\
\hline Air limbah & $\mathrm{kg}$ & 253.390 & 1.378 .140 & 309.699 & 1.941 .229 \\
\hline Kotoran sapi & $\mathrm{kg}$ & 124.014 & 674.689 & 151.663 & 950.336 \\
\hline
\end{tabular}


Analisis inventori juga berfungsi untuk menentukan hotspot penggunaan bahan dan energi tertinggi atau sumber limbah terbesar. Tabel 2 dan Tabel 3 menunjukkan penggunaan listrik lebih besar di koperasi dibandingkan gabungan peternak. Hal ini dikarenakan, para peternak hanya menggunakan energi listrik untuk penerangan kandang saat malam hari. Penggunaan listrik ini dapat menjadi pertimbangan untuk pengembangan koperasi ke depannya. Data input dan output proses koperasi dapat dilihat pada Tabel 3. Air limbah yang dihasilkan berasal dari air bekas pencucian tangki susu dan ruang pendingin susu.

Transportasi susu dari koperasi MJM ke KPSBU menggunakan truk berbahan bakar solar yang membawa tangki susu berkapasitas 5 L. Jarak yang dihitung sekali perjalanan ketika membawa susu segar yaitu $52 \mathrm{~km}$. Sekali perjalanan penjemputan susu murni membawa $5135 \mathrm{~kg}$ sehingga input transportasi untuk analisis dampak sebesar 267,02 tkm (ton.km).

\section{Analisis Dampak}

Setiap inventori yang terdapat dalam siklus dilakukan perincian polutan apa yang dikeluarkan ke lingkungan. Polutan tersebut dikelompokkan sesuai kategori dampaknya. Perhitungan dampak yang dilakukan umumnya berupa nilai inventori dikali dengan faktor emisi dampak yang dikeluarkan. Faktor emisi dan polutan lain yang dihasilkan dari suatu proses maupun inventori terdapat dalam database SimaPro.

Tabel 3. Data inventori proses koperasi selama 12 bulan

\begin{tabular}{lcr}
\hline \multicolumn{1}{c}{ Data } & Satuan & \multicolumn{1}{c}{ Jumlah } \\
\hline Input & & \\
Listrik & $\mathrm{kWh}$ & $12.010,13$ \\
Sabun & $\mathrm{kg}$ & 58,95 \\
Air pencucian & $\mathrm{L}$ & $17.884,8$ \\
Output & & \\
Susu segar & $\mathrm{kg}$ & $557.550,60$ \\
Air limbah & $\mathrm{L}$ & 17951,04 \\
\hline
\end{tabular}

Tabel 4. Besaran emisi GRK, asidifikasi dan eutrofikasi per $1 \mathrm{~kg}$ susu segar

\begin{tabular}{lcc}
\hline $\begin{array}{l}\text { Kategori } \\
\text { Dampak }\end{array}$ & Satuan & Total \\
\hline Gas rumah kaca & $\mathrm{kg} \mathrm{CO}_{2}$ eq & 3,16 \\
Asidifikasi & $\mathrm{kg} \mathrm{SO}_{2}$ eq & 0,00639 \\
Eutrofikasi & $\mathrm{kg} \mathrm{PO}_{4}{ }^{3-}$ eq & 0,0119 \\
\hline
\end{tabular}

Hasil perhitungan dampak dari Tabel 4 menunjukkan bahwa setiap kegiatan siklus hidup produksi $1 \mathrm{~kg}$ susu segar menghasilkan emisi GRK, asidifikasi maupun eutrofikasi. Setiap kegiatan yang mengeluarkan emisi diakumulasi sehingga didapatkan besaran emisi dalam satu siklus produksi susu segar. Emisi $\mathrm{CH}_{4}$ berasal dari fermentasi enterik dan kotoran sapi. Menurut Horacio dan Rebecca (2017), kotoran sapi di kandang mengeluarkan emisi
$\mathrm{CH}_{4}$ yang besarannya bergantung pada suhu lingkungan dan luas permukaan yang terpapar kotoran. Emisi $\mathrm{NH}_{3}$ bergantung pada $\mathrm{N}$ amoniak, $\mathrm{pH}$, suhu, dan luas permukaan. Hal ini menyebabkan semakin besarnya emisi yang ke udara saat kotoran sapi tidak langsung dilakukan pengelolaan.

Penggunaan bahan bakar untuk transportasi, penggunaan listrik dan penggunaan pupuk mengeluarkan gas $\mathrm{CO}_{2}$ secara tidak langsung. Kandungan nitrogen dalam kotoran sapi dengan adanya proses denitrifikasi akan mengeluarkan gas $\mathrm{N}_{2} \mathrm{O}$. Sumber polutan penyebab asidifikasi yang mengeluarkan emisi SO2 berasal dari penggunaan bahan bakar dan penggunaan listrik. Emisi $\mathrm{NH}_{3}$ dihasilkan dari emisi limbah cair yang tercampur dengan kotoran sapi. Sumber polutan penyebab asidifikasi yang mengeluarkan emisi NOx berasal dari penggunaan bahan bakar dan penggunaan listrik. Bahan organik yang berasal dari kotoran sapi dapat menyebabkan kandungan ammonia dan kadar nitrat dalam perairan melebihi batas kadar dalam perairan alami. Dampak eutrofikasi berasal dari senyawa fosfat dan COD yang tinggi didalam badan air. Kotoran sapi yang sudah bercampur dengan air limbah maupun air alami dari aktifitas peternakan menjadi sumber emisi fosfat dan COD (Taufiq et al., 2016).

Produksi susu di Iran menunjukkan emisi dampak lingkungan produksi $1 \mathrm{~kg}$ susu sebesar 1,831 $\mathrm{kg} \mathrm{CO} 2 \mathrm{eq} / \mathrm{kg} ; 0,00797 \mathrm{~kg} \mathrm{SO} 2 \mathrm{eq} / \mathrm{kg}$ dan $0,0034 \mathrm{~kg}$ $\mathrm{PO}_{4}{ }^{3-} \mathrm{eq} / \mathrm{kg}$ (Soltanali et al., 2015). Emisi GRK dan eutrofikasi produksi susu di koperasi MJM lebih besar dibanding produksi susu di Iran karena adanya perbedaan kegiatan di peternakan. Produksi susu di Iran termasuk kategori peternakan modern sehingga kegiatan transportasi lebih sedikit. Selain itu, pada peternakan kecil di Rancabali belum terdapat pengolahan kotoran sapi sehingga mengeluarkan emisi yang lebih besar.

Analisis dampak dilakukan pengelompokkan berdasarkan bagian-bagian dalam ruang lingkup. Dampak lingkungan dari bagian penyediaan pakan dapat dilihat pada Tabel 5. Produksi ampas tahu memberikan dampak GRK, asidifikasi dan eutrofikasi terbesar. Dampak emisi GRK, asidifikasi dan eutrofikasi per kategori pakan dapat dilihat pada Tabel 6. Dampak emisi GRK, asidifikasi dan eutrofikasi terkecil yaitu pada kategori pakan 1. Hal ini menunjukkan adanya pengaruh kuantitas pemberian pakan, produksi susu murni dan kotoran yang dihasilkan. Kategori pakan 1 dapat dikatakan paling efisien karena dengan kuantitas pakan yang paling besar menghasilkan produksi susu murni yang paling besar dan mengeluarkan kotoran sapi yang sedikit.

Dampak lingkungan dari bagian kegiatan di peternakan dapat dilihat pada Tabel 7. Emisi dari kotoran sapi memberi dampak terbesar untuk ketiga kategori. Emisi kedua terbesar untuk ketiga kategori dampak yaitu penggunaan listrik. Dampak 
lingkungan dari bagian kegiatan di koperasi dapat dilihat pada Tabel 8. Dampak terbesar di ketiga kategori dampak pada kegiatan di koperasi yaitu penggunaan listrik. Dampak lingkungan dari bagian transportasi dapat dilihat pada Tabel 9. Dampak terbesar GRK terdapat di transportasi pengambilan rumput walaupun jaraknya lebih dekat. Transportasi pengambilan rumput perlu dilakukan bolak-balik karena menggunakan kendaraan motor yang kapasitasnya terbatas. Hal ini menyebabkan kebutuhan bahan bakar untuk transportasi semakin besar dan mengeluarkan gas $\mathrm{CO}_{2}$ lebih banyak. Transportasi susu dari KSU MJM ke KPSBU menghasilkan nilai dampak asidifikasi dan eutrofikasi paling besar. Hal ini berkaitan dengan perbedaan kendaraan yang digunakan dan jenis bahan bakar. Transportasi susu ke IPS menggunakan truk dengan bahan bakar solar yang lebih banyak menghasilkan gas $\mathrm{SO}_{2}$ dan polutan $\mathrm{PO}_{4}{ }^{3-}$ yang lebih banyak dibandingkan motor maupun mobil pick up dengan bahan bakar bensin.

\section{Interpretasi Hasil}

Gambar 2 menunjukkan kontribusi masingmasing bagian untuk setiap kategori dampak yang terdiri dari pakan, kegiatan peternakan, kegiatan koperasi dan transportasi. Bagian pakan memberikan dampak lingkungan terbesar untuk kategori GRK dan asidifikasi. Bagian proses di peternakan memberikan dampak terbesar untuk kategori dampak eutrofikasi. Dampak eutrofikasi yang besar disebabkan oleh kotoran sapi yang dihasilkan pada produksi susu mengandung nitrogen sebagai polutan yang mempunyai efek penurunan kualitas perairan karena adanya proses eutrofikasi. Menurut Thoma et al. (2013), pakan ternak dan manajemen kotoran sapi menjadi salah satu faktor utama polusi udara dalam hasil penelitian dampak lingkungan pada peternakan sapi perah di Amerika Serikat (AS).

Tabel 5. Besaran emisi GRK, asidifikasi dan eutrofikasi bagian pakan

\begin{tabular}{lllll}
\hline & Satuan & Rerumputan & Konsentrat & Ampas Tahu \\
\hline GRK & $\mathrm{kg} \mathrm{CO}_{2}$ eq & $1,81 \mathrm{E}-03$ & 0,345 & 2,17 \\
Asidifikasi & $\mathrm{kg} \mathrm{SO}_{2}$ eq & $9,12 \mathrm{E}-05$ & $8,15 \mathrm{E}-04$ & $2,20 \mathrm{E}-03$ \\
Eutrofikasi & $\mathrm{kg} \mathrm{PO}_{4}{ }^{3-} \mathrm{eq}$ & $2,51 \mathrm{E}-05$ & $7,53 \mathrm{E}-04$ & $2,37 \mathrm{E}-03$ \\
\hline
\end{tabular}

Tabel 6. Besaran emisi GRK, asidifikasi dan eutrofikasi sesuai kategori pakan

\begin{tabular}{lllll}
\hline & Satuan & Pakan 1 & Pakan 2 & Pakan 3 \\
\hline GRK & $\mathrm{kg} \mathrm{CO}_{2}$ eq & 0,387 & 0,64 & 1,43 \\
Asidifikasi & $\mathrm{kg} \mathrm{SO}_{2}$ eq & 0,0017 & 0,00287 & 0,00658 \\
Eutrofikasi & $\mathrm{kg} \mathrm{PO}_{4}{ }^{3-}$ eq & 0,00496 & 0,00867 & 0,0206 \\
\hline
\end{tabular}

Tabel 7. Besaran emisi GRK, asidifikasi dan eutrofikasi kegiatan di peternakan

\begin{tabular}{llllll}
\hline & Satuan & Sabun & Listrik & $\begin{array}{l}\text { Limbah } \\
\text { cair }\end{array}$ & $\begin{array}{l}\text { Kotoran } \\
\text { sapi }\end{array}$ \\
\hline GRK & $\mathrm{kg} \mathrm{CO}_{2}$ eq & $7,18 \mathrm{E}-04$ & $3,85 \mathrm{E}-03$ & $-1,27 \mathrm{E}-01$ & $5,80 \mathrm{E}-01$ \\
Asidifikasi & $\mathrm{kg} \mathrm{SO}_{2}$ eq & $2,70 \mathrm{E}-06$ & $1,68 \mathrm{E}-05$ & $-2,80 \mathrm{E}-04$ & $2,63 \mathrm{E}-03$ \\
Eutrofikasi & $\mathrm{kg} \mathrm{PO}_{4}{ }^{3-} \mathrm{eq}$ & $2,38 \mathrm{E}-06$ & $2,04 \mathrm{E}-05$ & $-9,00 \mathrm{E}-05$ & $8,49 \mathrm{E}-03$ \\
\hline
\end{tabular}

Tabel 8. Besaran emisi GRK, asidifikasi dan eutrofikasi kegiatan di koperasi

\begin{tabular}{llcclc}
\hline & Satuan & Listrik & Sabun & $\begin{array}{c}\text { Limbah cair } \\
\text { yang diolah }\end{array}$ & Air bersih \\
\hline GRK & $\mathrm{kg} \mathrm{CO}_{2}$ eq & $2,50 \mathrm{E}-02$ & $2,50 \mathrm{E}-04$ & $1,79 \mathrm{E}-05$ & $2,10 \mathrm{E}-04$ \\
Asidifikasi & $\mathrm{kg} \mathrm{SO}_{2} \mathrm{eq}$ & $1,08 \mathrm{E}-04$ & $9,41 \mathrm{E}-07$ & $1,32 \mathrm{E}-07$ & $5,96 \mathrm{E}-07$ \\
Eutrofikasi & $\mathrm{kg} \mathrm{PO}_{4}{ }^{3-} \mathrm{eq}$ & $1,32 \mathrm{E}-04$ & $8,28 \mathrm{E}-07$ & $4,35 \mathrm{E}-07$ & $9,45 \mathrm{E}-08$ \\
\hline
\end{tabular}

Tabel 9. Besaran emisi GRK, asidifikasi dan eutrofikasi kegiatan transportasi

\begin{tabular}{lllll}
\hline & \multicolumn{1}{c}{ Satuan } & $\begin{array}{c}\text { Transportasi } \\
\text { pakan }\end{array}$ & $\begin{array}{c}\text { Transportasi susu } \\
\text { ke koperasi }\end{array}$ & $\begin{array}{c}\text { Transportasi } \\
\text { susu ke IPS }\end{array}$ \\
\hline GRK & $\mathrm{kg} \mathrm{CO}_{2} \mathrm{eq}$ & $8,02 \mathrm{E}-02$ & $3,85 \mathrm{E}-02$ & $4,57 \mathrm{E}-02$ \\
Asidifikasi & $\mathrm{kg} \mathrm{SO}_{2} \mathrm{eq}$ & $2,66 \mathrm{E}-04$ & $1,71 \mathrm{E}-04$ & $4,06 \mathrm{E}-04$ \\
Eutrofikasi & $\mathrm{kg} \mathrm{PO}_{4}{ }^{3-} \mathrm{eq}$ & $6,74 \mathrm{E}-05$ & $4,70 \mathrm{E}-05$ & $8,65 \mathrm{E}-05$ \\
\hline
\end{tabular}




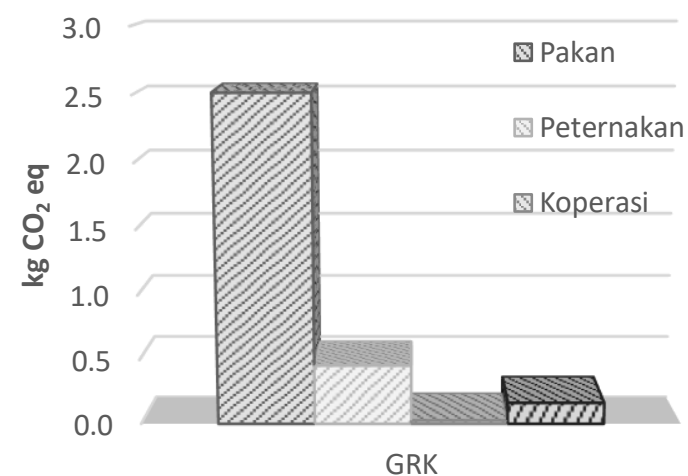

(a)

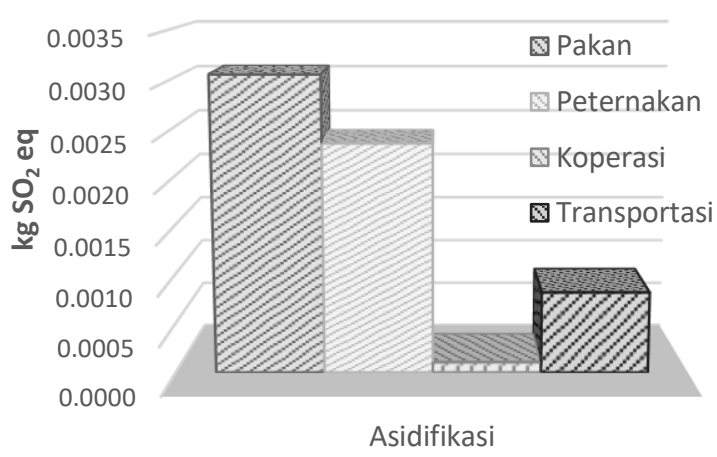

(b)

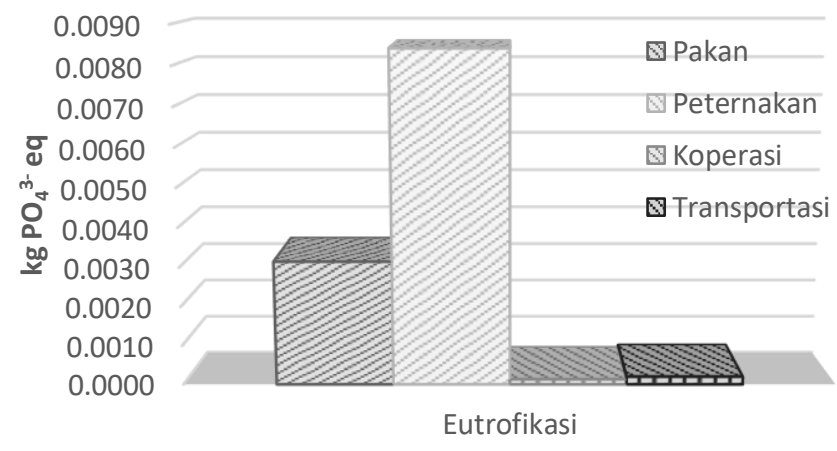

(c)

Gambar 2. Nilai emisi masing-masing bagian untuk kategori dampak : (a) GRK, (b) Asidifikasi, (c) Eutrofikasi

Penyediaan pakan dapat dikategorikan termasuk bagian kegiatan dari peternakan. Hal ini menunjukkan dampak lingkungan dari produksi susu di peternakan lebih tinggi dibandingkan dengan transportasi pakan, transportasi susu dan kegiatan di koperasi. Hasil penelitian LCA pada aktivitas supply chain susu menunjukkan hal yang sama (Putri et al., 2014).

Dampak GRK, asidifikasi dan eutrofikasi pada produksi ampas tahu termasuk yang tertinggi (Tabel 5) karena adanya proses pemupukan saat penanaman kedelai, dampak dari proses transportasi antar negara dan proses produksi pembuatan tahu. Dampak GRK tertinggi dari satu siklus produk tofu yaitu pada unit transportasi bahan baku kedelai dari tempat kultivasi kedelai dari negara AS ke pabrik produksi tofu. Transportasi kedelai menggunakan kereta, kapal dan truk yang membutuhkan bahan bakar lebih banyak. Hal ini menyebabkan tingginya dampak GRK (Sukmana et al., 2019). Perbaikan yang dapat dilakukan yaitu memilih bahan tambahan pakan yang lebih kecil dampaknya, misal : mengganti ampas tahu dengan onggok. Onggok berasal dari singkong yang banyak dibudidayakan di Indonesia sehingga dampak lingkungan dari kegiatan transportasi lebih kecil dibanding dampak dari penyediaan ampas tahu.

Hotspot kegiatan di peternakan berasal dari manur. Manur yang terdiri dari feses dan urin dengan unsur N, P dan K dihasilkan berbeda-beda oleh sapi perah, tergantung kondisi fisiologi sapi (Tanuwiria, 2010). Manur yang dihasilkan dari peternakan kecil biasanya berbentuk padat dan langsung diaplikasi ke tanah menjadi pupuk maupun dibuang langsung ke aliran air menuju sungai. Emisi GRK dan $\mathrm{NH}_{3}$ dihasilkan selama pengaplikasian manur ke lahan sebagai pupuk kandang pada peternakan kecil. Pengaplikasian manur ke tanah setiap hari atau setiap minggu dapat menyebabkan limpasan dan pencucian saat terjadi hujan yang mengakibatkan potensi eutrofikasi dan hilangnya nutrisi tanah (Horacio dan Rebecca, 2017).

Hasil polutan ini perlu dilakukan pengolahan lebih lanjut untuk mengurangi dampaknya ke lingkungan. Pengolahan manur dapat dilakukan dengan cara laguna, biogas, pupuk dan kompos cacing. Pengolahan yang bernilai ekonomis dan memanfaatkan tingginya gas metan pada manur yaitu biogas. Biogas dapat menjadi alternatif energi dan sekaligus mengolah manur dengan baik. Energi biogas yang dihasilkan dapat digunakan untuk penerangan lampu 60-100 W selama 6 jam, memasak 3 jenis makanan untuk 5-6 orang, pengganti $0,7 \mathrm{~kg}$ bensin dan menjalankan motor 1 pk selama 2 jam (Haryati, 2006). Pengelolaan manur memainkan peran kunci pada strategi pengurangan emisi GRK. Pembuatan biogas dengan proses anaerobic digester (AD) merupakan strategi paling efektif untuk mengurangi emisi GRK baik dari energi maupun 
manur. Namun, AD juga meningkatkan emisi $\mathrm{NH}_{3}$ selama penyimpanan karena proses mineralisasi yang terjadi pada digester (Horacio dan Rebecca, 2017). Kegiatan pengurangan dampak lingkungan terkait pengganti ampas tahu dan pengolahan manur maka perlu dilakukan salah satu peternakan menjadi model pemberian pakan yang baik dan pengolahan manur menjadi biogas. Kegiatan ini perlu dukungan dari manajemen koperasi dan pemerintah. Hal ini terkait dengan hasil analisis dampak berdasarkan kategori pemberian pakan maka pemberian pakan terbaik (kategori pakan 1) dengan memberikan asupan nutrisi yang maksimal kepada sapi perah (Tabel 1) dan memberikan dampak lingkungan yang kecil (Tabel $6)$.

\section{KESIMPULAN DAN SARAN}

\section{Kesimpulan}

Produksi susu segar dalam kajian LCA ini mulai dari penanaman rumput sebagai pakan ternak, transportasi pakan, kegiatan di peternakan, transportasi susu, kegiatan di koperasi dan distribusi susu segar ke IPS. Input yang digunakan yaitu air, rumput, konsentrat, pakan tambahan, dan sabun. Energi yang dibutuhkan untuk penerangan kandang dan menjalankan mesin yaitu listrik. Bensin dan solar menjadi bahan bakar yang digunakan untuk mendukung transportasi. Setiap kegiatan menghasilkan emisi ke udara dan air. Berdasarkan analisis siklus hidup cradle to gate $1 \mathrm{~kg}$ susu segar, produk susu memberikan dampak lingkungan kategori GRK, asidifikasi dan eutrofikasi sebesar 3,16 $\mathrm{kg} \mathrm{CO}_{2}$ eq, $0,00639 \mathrm{~kg} \mathrm{SO}_{2}$ eq, dan 0,0119 $\mathrm{kg} \mathrm{PO}_{4}{ }^{3-}$. Dampak terbesar terdapat pada kegiatan pengadaan/produksi ampas tahu, penggunaan listrik di KSU MJM dan manur. Alternatif penurunan dampak lingkungan dapat dilakukan antara lain : bahan tambahan pakan yaitu ampas tahu diganti dengan bahan pakan tambahan yang lebih ramah lingkungan (onggok); pengolahan manur dapat dilakukan untuk produksi biogas.

\section{Saran}

Koperasi dapat mengatur kembali penggunaan listrik dalam kegiatan di koperasi. Koperasi diharapkan membantu ketersediaan bahan pakan tambahan pengganti ampas tahu. Para peternak bekerjasama dengan koperasi dan pemerintah menerapkan pengolahan manur menjadi biogas dimulai dari per kelompok peternak.

\section{DAFTAR PUSTAKA}

[BPS] Badan Pusat Statistik. 2019. Statistik Indonesia Tahun 2019. Jakarta Pusat (ID): Badan Pusat Statistik.

[ISO] International Standard Organization 14040. 2006. Enviromental Management, Life Cycle
Assesment, Requirements and Guidelines. Switzerland (CH): Geneva.

[Kemenperin] Kementerian Perindustrian. 2014. Konsumsi susu masih 11,09 liter per kapita [Internet]. [diunduh 09 Des 2019]. Tersedia pada https://kemenperin.go.id/artikel/8890/Konsu msi-Susu-Masih-11,09-Liter-per-Kapita

[Perpres] Peraturan Presiden Republik Indonesia. 2011. Perpres No. 61 Tahun 2011 tentang Rencana Aksi Nasional Penurunan Emisi Gas Rumah Kaca (RAN GRK). Jakarta (ID): Bappenas.

Castanheira EG, Dias AC, Arroja L, dan Amaroc R. 2010. The environmental performance of milk production on a typical Portuguese dairy farm. Agri Syst. 103: 498-507.

Christie KM, Rawnsley RP, dan Eckard RJ. 2011. A whole farm systems analysis of greenhouse gas emissions of 60 Tasmanian dairy farms. Anim Feed Sci Technol. 166-167:653-662.

Firman A. 2007. Manajemen Agribisnis Sapi Perah. Bandung (ID): Fakultas Peternakan Universitas Padjajaran.

Foley JA, Ramankutty N, Brauman KA, Cassidy ES, Gerber JS, Johnston M, Mueller ND, O'Connell C, Ray DK, dan West PC. 2011. Solutions for a cultivated planet. Nature. 478: 337-342.

Harjanto TR, Fahrurrozi M, Bendiyasa IM. 2012. Life cycle assesment pabrik semen PT. Holcim Indonesia Tbk. Pabrik Cilacap: Komparasi antara Bahan Bakar Batubara dengan Biomassa. Jurnal Rekayasa Proses 6(2): 5158.

Haryati T. 2006. Limbah Peternakan yang menjadi Sumber Energi Alternatif. Bogor (ID) : Balai Penelitian Ternak Bogor.

Horacio AA dan Rebecca AL. 2017. Evaluating greenhouse gas emissions from dairy manure management practices using survey data and lifecycle tools. J Cleaner Prod. 143 : 169-179.

Permana IG, Suryahadi, Qurimansari E. 2012. Greenhouses Gases Emissions from Dairy Cattle in Indonesia. Proceedings of the Second International Seminar on Animal Industry 2012. Jakarta, Indonesia. 5-6 Juli 2012.

Purwaningsih IW. 2016. Penilaian daur hidup (Life Cycle Assessment) Gula Tebu di PG Subang, Jawa Barat. [Thesis]. Bogor: Institut Pertanian Bogor.

Putri RP, Tama IP, Yuniarti R. 2014. Evaluasi Dampak Lingkungan pada Aktivitas Supply Chain Produk Susu KUD Batu dengan Implementasi Life Cycle Assessment (LCA) dan Pendekatan Analytic Network Process (ANP). Jurnal Rekayasa dan Manajemen Sistem Industri. Vol 2 No 4.

Soltanali H, Emadi B, Rohani A, Khojastehpour M, Nikkhah A. 2015. Life Cycle Assessment 
modeling of milk production in Iran. Information Processing In Agriculture. 2 : 101-108.

Sukmana B, Surjandari I, Muryanto, Setiawan AAR, Wiloso EI. 2019. Global Warming Impacts Study on Tofu Products in Mampang Prapatan Small and Medium Enterprises with Life Cycle Assessment Methods. IJoLCAS. 3 (2): 9-24.

Tanuwiria UH. 2010. Optimalisasi Pakan Lokal Dalam Mendukung Peternakan Sapi Perah di Citarum Hulu. Seminar Nasional 2010Pembangunan Peternakan Berkelanjutan 2. Unpad. Bandung. 3-4 November 2010.

Taufiq FM, Padmi T, Rahardyan B. 2016. Life cycle assessment of dairy farms. Rev Environ Health 2016. 31(1): 187-190.
Thoma G, Popp J, Shonnard D, Nutter D, Matlock M, Ulrich R, KelloggW, Kim DS, Neiderman Z, Kemper N, Adomd F, East C. Regional analysis of greenhouse gas emissions from USA dairy farms: a cradle to farm-gate assessment of the American dairy industry circa 2008. International Dairy Journal 2013. 31: 29-40.

Widyastuti, Purwanto, dan Hadiyanto. 2013. Upaya Pengelolaan Lingkungan Usaha Peternakan Sapi di Kawasan Usahatani Terpadu. Prosiding Seminar Nasional Pengelolaan Sumber Daya Alam dan Lingkungan 2013. Semarang, Indonesia. 10 September 2013. 